\title{
Microwave and Nanotechnology Advanced Solutions to Improve Eco-friendly Cotton's Coloration and Performance Properties
}

\author{
T. Abou Elmaaty ${ }^{1 *}$, Kh. El-Nagar ${ }^{2}$, D.N. Zaghloul ${ }^{1}$, Kh. Sayed-Ahmed ${ }^{3}$, Sh. El- \\ Kadi $^{4}$, E. Abdelaziz ${ }^{5}$ \\ ${ }^{1}$ Department of Textile Printing, Dyeing and Finishing, Faculty of Applied Arts, Damietta \\ University, Egypt; \\ ${ }^{2}$ Textile Metrology Lab., National Institute for Standards, AL Haram, Giza, Egypt; \\ ${ }^{3}$ Department of Agricultural Chemistry, Faculty of Agriculture, Damietta University, Egypt; \\ ${ }^{4}$ Department of Agricultural Microbiology, Faculty of Agriculture, Damietta University, \\ Egypt, \\ ${ }^{5}$ Department of Textile Printing, Dyeing and Finishing, Faculty of Applied Arts, Banha \\ University, Egypt.
}

\begin{abstract}
THIS RESEARCH aims to utilize microwave energy and nanotechnology to improve the printability and performance of cotton prints via screen printing technique. Each cotton sample was individually pre-treated by microwave power ranged from 300 to 700 watts and for a period ranged from 1 to $9 \mathrm{~min}$. Afterwards the optimum sample was printed by printing paste containing Remazol ${ }^{\mathrm{TM}}$ reactive dye and silver nanoparticles (Ag-NPs) with different concentrations. The printed samples were fixed using microwave energy then were subjected to steaming or thermo-fixation. The obtained results clarified that, the prints obtained using microwave and Ag-NPs were found to have better color strength, fastness properties, antibacterial behavior and surface morphology when they were compared to the conventional techniques using thermo-fixation and steaming.
\end{abstract}

Keywords: Microwave, Nanotechnology, Printing, Cotton, Silver nanoparticles, Antimicrobial textiles.

\section{Introduction}

Cotton is the most widely used of the textile fibers because of its intrinsic properties of biodegradability, breathability, hydrophilicity, comfortability and versatility, etc. Therefore, it is an excellent substrate for dyeing and printing as well as for imparting high performance with additional functionalities. Typical examples of such functionalities are antimicrobial activity, softness, easy-care, flame retardancy, and water \&oil repellency [1-3]. To achieve this task, traditional wet methods were used for applying coloration and finishes, however they require large amounts of chemicals, water and energy. On the contrary, microwave (MW) is a dry processing technique that provide a solution to reduce the use of the above mentioned three resources [4].

The mechanism of microwave heating can be explained as follows:Many materials with large dipole moments, such as water, are rotated or vibrated vigorously in the presence of a magnetic field caused by the frequency of the alternating current of microwave as (the $2,450 \mathrm{MHz}$ microwave energy), then they are heated by quick energy conversion from the above kinetic energy. As a result, microwaves can usually heat various materials more quickly and homogeneously than conventional methods such as heat conduction or heat convection $[5,6]$.

(MW) energy applications have been used for many years in industrial technology. According to the previous literatures, (MW) irradiation has been successfully applied to a number of classical reactions such as dyeing, finishing and drying [712]. Microwave can provide various fabrics [13-17] with high coloration efficiency and color fastness properties in short heating time and low energy. Also, it is easy to be controlled and it is pollution free heating process. So, it is convenient for continuous production in textile industry[18, 19].

On the other hand, the importance of textile's functionalization with nanoparticles (NPs)

${ }^{*}$ Corresponding author: Prof. Dr. Tarek Abou Elmaaty

Email: tasaid@hotmail.com

DOI: 10.21608/EJCHEM.2018.2927.1270

(C)2017 National Information and Documentation Center (NIDOC) 
materials such as $(\mathrm{Ag}),(\mathrm{Au}),(\mathrm{Pt})$ and $(\mathrm{Cu})$ have been increased in the recent years because of their electronic, optical, biological, chemical and physical properties. Various methodologies have been created using metal NPs to improve textiles functions as flame retardant, hydrophobic, antistatic, UV-protective and antimicrobial agents, etc. [20, 21]. Based on literature, nano silver particles (Ag-NPs) are widely used due to their antimicrobial behaviors [22-28]. It provides biological effect due to their large surface area in addition to the associated potential to release silver ions and it has been applied on different textile materials [28].

To the best of our knowledge, microwave has been utilized in textile dyeing applications and proved to be efficient. However, using MW in textile printing has not been explored as much. Therefore, the aim of this study is to evaluate microwave irradiation as a source of heat for pretreatment of cotton fabrics and subsequent drying and fixing of print simplemented Ag-NPs in onestep. So, this work gives an environmentally eco-friendly solution for printing and finishing processes.

\section{Experimental}

\section{Materials and instrumentation}

In this study, $100 \%$ scoured and bleached plain weave cotton fabrics $\left(200 \mathrm{~g} / \mathrm{m}^{2}\right)$ were used, commercial reactive dye namely (Remazol blue RR gran) which based on methylsulphonylchloromethylpyramidine, C.I. RB and Ludigol namely (Seracon M-lu) were received from (Dystar), sodium alginate (low viscosity), cream coloured powder, manufactured by Loba Chemie Chemical Company, were used. All other chemicals used during work such as urea, sodium bicarbonate were of laboratory grade chemicals.

Microwave treatment: Daewoo electronic Korea, Model KqG-1N4A of maximum power 1000W.

\section{Methods}

\section{Conventional printing paste}

Guide formulation for aqueous printing using flat screen printing technique follows:

\begin{tabular}{lc}
\hline Printing paste components & g/kg paste \\
\hline Reactive dyes & 40 \\
Urea & 100 \\
Sodium alginate $(12 \%)$ & 500 \\
Sodium bicarbonate & 30 \\
Ludigol & 10 \\
Water & $\mathrm{X}$ \\
Total & 1000 \\
\hline
\end{tabular}

Fabric treatment

Cotton fabrics were treated by microwave irradiation using microwave oven (IEC 705) that has the continuously adjustable power of 250$1000 \mathrm{Watt}$, the microwave frequency 2,450 MHZ.

Procedure for studying the effect of microwave treatment power

Cotton fabric samples were placed in the microwave oven and exposed to microwave irradiation at various power settings, i.e. 300, 400, 500,600 and $700 \mathrm{w}$ for different durations 1,3,5,7 and $9 \mathrm{~min}$, respectively.

Thereafter, the cotton fabrics were removed from the microwave oven and allowed to cool slowly at the room environmental condition $\left(20^{\circ} \mathrm{C}\right.$ \pm 2 and relative humidity $65 \% \pm 2$ ), followed by printing and subsequent fixation according to the conventional technique by steaming at $103^{\circ} \mathrm{C}$ for $10 \mathrm{~min}$.

Procedure for studying the effect of microwave treatment time

Cotton fabric samples were placed in the microwave oven and exposed to microwave irradiation at power settings $600 \mathrm{~W}$ and for different durations 1,3,5,7 and $9 \mathrm{~min}$, respectively.

After the irradiation treatment, the cotton fabrics were removed from the microwave oven and allowed to cool slowly at the room environmental condition $\left(20^{\circ} \mathrm{C} \pm 2\right.$ and relative humidity $65 \% \pm 2 \%$ ). Followed by printing and subsequent fixation according to the conventional technique by steaming at $103^{\circ} \mathrm{C}$ for $10 \mathrm{~min}$.

\section{Fixation methods}

After printing the optimum treated fabric samples were subjected directly, i.e. before drying to microwave irradiation for various periods of time ranging between 1 to $9 \mathrm{~min}$ at different microwave powers $(400,500,600,700,800$, 900 and $1000 \mathrm{~W})$. For the sake of comparison, 
control samples of cotton fabrics were printed with the same paste, dried and subjected to fixation according to the conventional technique, i.e. either for steaming at $103^{\circ} \mathrm{C}$ for $10 \mathrm{~min}$. or thermo-fixation for $5 \mathrm{~min}$ at $180^{\circ} \mathrm{C}$ according to (Dystar) technical data sheet for Remazol ${ }^{\mathrm{TM}}$ dye.

After fixation, the fabric samples were washed according to the aforementioned procedure in the experimental section followed by drying at ambient conditions and assessed for color strength $(\mathrm{K} / \mathrm{S})$ as well as overall fastness properties. NPs)

Green synthesis of silver nanoparticles (Ag-

The silver nanoparticles in this study were prepared according to the method described in Literature [29] with an improved modification. AgNPs were synthesized using Plucheadioscoridis Leaves extract $(\mathrm{Pd})$ with different volumes. Six milliliters of $\mathrm{Pd}$ were mixed with $45 \mathrm{ml} \mathrm{AgNO}_{3}$ (5 mM) in $100 \mathrm{~mL}$ Erlenmeyer flask. While, 20 $\mathrm{ml}$ of $\mathrm{Pd}$ were added to $45 \mathrm{ml} \mathrm{AgNO}_{3}(20 \mathrm{mM})$ in other flask. The change in color from colorless to colloidal reddish brown indicted complete reduction of $\mathrm{AgNO}_{3}$ to $\mathrm{Ag}-\mathrm{NPs}$.

Procedure for studying the effect of silver nanoparticles on cotton fabrics

Cotton fabrics were placed in the microwave oven and then treated with microwave irradiation at $600 \mathrm{~W}$ for $5 \mathrm{~min}$. After the irradiation treatment, the cotton fabrics were removed from the microwave oven and allowed to cool slowly at the room temperature followed by flat screen printing and fixation in microwave at $700 \mathrm{~W}$ for $3 \mathrm{~min}$. Ag-NPs were added to printing paste with different concentrations and volumes $(10-40 \mathrm{ml})$. Ag-NPs synthesized using $6 \mathrm{ml} \mathrm{Pd}$ were used at various volumes $\left[10\left(\mathrm{~T}_{1}\right), 20\left(\mathrm{~T}_{2}\right), 30 \mathrm{ml}\left(\mathrm{T}_{3}\right)\right.$ and $40 \mathrm{ml}\left(\mathrm{T}_{4}\right)$ ]. Therefore, Ag-NPs formed by $20 \mathrm{ml}$ Pd were added with the same volumes [10 $\left(\mathrm{T}_{5}\right)$, $20\left(\mathrm{~T}_{6}\right), 30\left(\mathrm{~T}_{7}\right)$ and $\left.40 \mathrm{ml}\left(\mathrm{T}_{8}\right)\right]$. Also, untreated paste with Ag-NPs ( $\left.\mathrm{T}_{0}\right)$ was used in printing to compare the Ag-NPs effect.

Guide formulation for aqueous printing using flat screen technique follows :

\begin{tabular}{ll}
\hline Printing paste components & \multicolumn{1}{c}{ g/kg paste } \\
\hline Reactive dyes & 40 \\
Urea & 100 \\
Sodium alginate (12\%) & 500 \\
Sodium bicarbonate & 30 \\
Ludigol & 10 \\
Ag-NPs & $\left(0 \_40\right) \mathrm{ml}$ \\
Water & $\mathrm{X}$ \\
Total & 1000 \\
\hline
\end{tabular}

\section{Washing}

After printing and fixation via microwave irradiation, steaming and thermo-fixation, the printed samples were subjected to washing through 3 stages as follows:

- $\quad$ Rinsing with warm water.

- $\quad$ Soaping with solution containing $2 \mathrm{ml} / \mathrm{l}$ soap $60^{\circ} \mathrm{C}$ for $15 \mathrm{~min}$.

- $\quad$ Rinsing with cold water.

Testing

Color Strength $(K / S)$ measurement

The color strength $(\mathrm{K} / \mathrm{S})$ of the printed cotton fabrics were measured using the (Konica Minolta spectrophotometer CM-3600 d) spectrophotometer (Minolta, Tokyo, Japan).

\section{Mechanical testing}

The tensile strength and percentage elongation at break of untreated and treated samples for different periods were carried out according to the standard method using a Shimadzu universal tester typeS-500 (C.R.T) (Japan) [30].

\section{SEM and EDX analysis}

Scanning electron microscope (SEM) images of conventional and microwave treated cotton fabrics were obtained using JEOL JXL-840A electron probe micro-analyzer equipped with energy disperse X-ray spectroscopy (EDX) for composition analysis.

Assessment of color fastness

Fastness to washing was performed using AATCC-61 Test Method [31]. Fastness to light was performed using AATCC-16 Test Method [32]. Fastness to rubbing was evaluated according to AATCC-8A Test Method [33].

\section{Antibacterial test}

Antibacterial activity assessment against $\mathrm{G}+\mathrm{ve}$ bacteria (Staphylococcus aureus \& Bacillus cereus), G-ve bacteria (Escherichia coli) and Candida utilis was evaluated qualitatively according to AATCC-147 Test Method [34] and expressed as zone of growth inhibition $\left(\mathrm{mm}^{2}\right)$.

\section{Results and Discussion}

This work exhibits a novel green procedure for printing cotton fabrics using microwave irradiation and silver nanoparticles to attain multifunctional functionality. Results obtained along with their appropriate discussion follow.

Microwave irradiation treatment of cotton fabrics Effect of microwave power on $K / S$

As is evident in Fig.1, increasing the

Egypt.J.Chem. 61, No.3 (2018) 
microwave treatment powers from 300 to $600 \mathrm{~W}$ for 5 min brings about a noticeable increase in the $\mathrm{K} / \mathrm{S}$ value until reached a maximum value at $(\mathrm{k} /$ $\mathrm{s}=31.3$ ), then decreased with a further increment. The main reason for this phenomenon is that, increasing the power of microwave up to $600 \mathrm{w}$, led to more rapid, uniform, efficient, and easy penetration of the dyestuff into the fabric i.e. higher absorbency.

On the contrary, the increasing in powers above $600 \mathrm{w}$ changed the thermal stability and the crystallinity of the treated fabrics so its absorption became lower than before. [19]

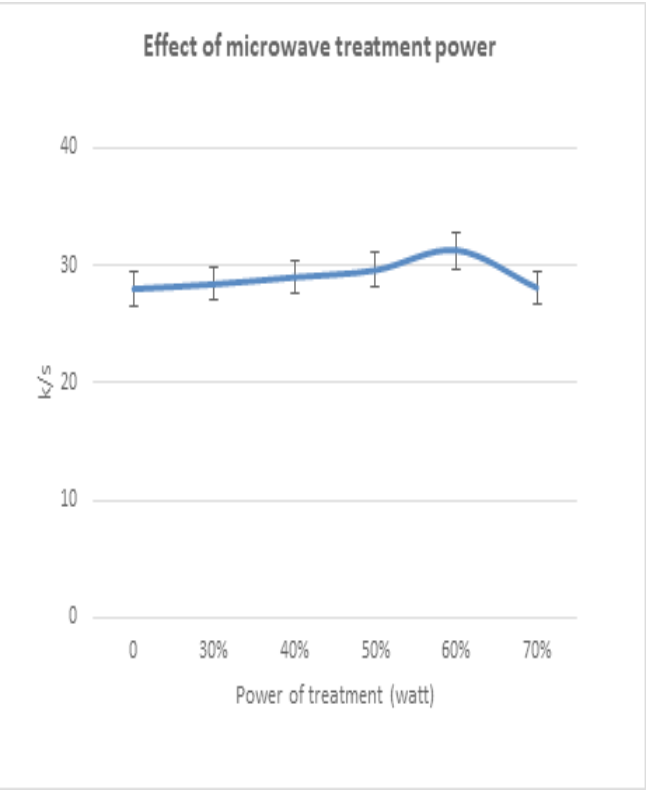

Fig.1. Effect of microwave powers on $(\mathrm{K} / \mathrm{S})$ of cotton fabrics at $5 \mathrm{~min}$.

Effect of microwave treatment time

As depicted in Fig. 2, increasing the microwave treatment times from 1 to $9 \mathrm{~min}$ at $600 \mathrm{w}$ brings about a noticeable increase in the $\mathrm{K} / \mathrm{S}$ value until reached a maximum value at $(\mathrm{k} / \mathrm{s}=31.3)$ at $6 \mathrm{~min}$, then decreased with a further increment. This may be attributed to the fact that, the increase of microwave time and power enhanced the fabric roughness which was favorable to improve the dye ability of cotton fabric.

On the contrary, the increasing in time above 6 min changed the crystallinity and the orientation of the treated cotton cellulose lead to lower absorbency. Accordingly, the optimum treatment time at power $600 \mathrm{w}$ was found to be $6 \mathrm{~min}(\mathrm{k} /$ $s=31.6)$. [10, 19].

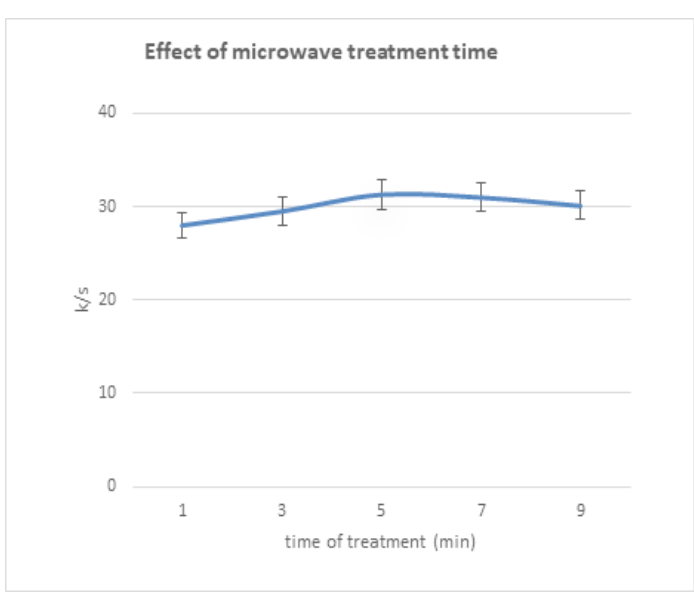

Fig.2. Effect of microwave time on $(\mathrm{K} / \mathrm{S})$ of cotton fabrics.

Fixation of cotton fabrics by microwave irradiation

Effect of microwave fixation power

It is clear from the data represented in Fig. 3 that, increasing the magnitude of microwave fixation powers from 400 to $1000 \mathrm{~W}$ for $3 \mathrm{~min}$ led to increase in $\mathrm{K} / \mathrm{S}$ value. It increased up to 700 $\mathrm{W}$, However, it decreased with further increase in power. The current data is expected since increase in the power at constant time is accompanied by an increase in the temperature. Accordingly, the rate of reaction between the reactive dye molecules and the hydroxyl groups of cotton increased. At relatively high power, i.e. $1000 \mathrm{~W}$, the opposite holds true where the $\mathrm{K} / \mathrm{S}$ decreased from 33 to 29.4 because of the decomposition and hydrolysis of some dye molecules as a result of over exposure to irradiation.

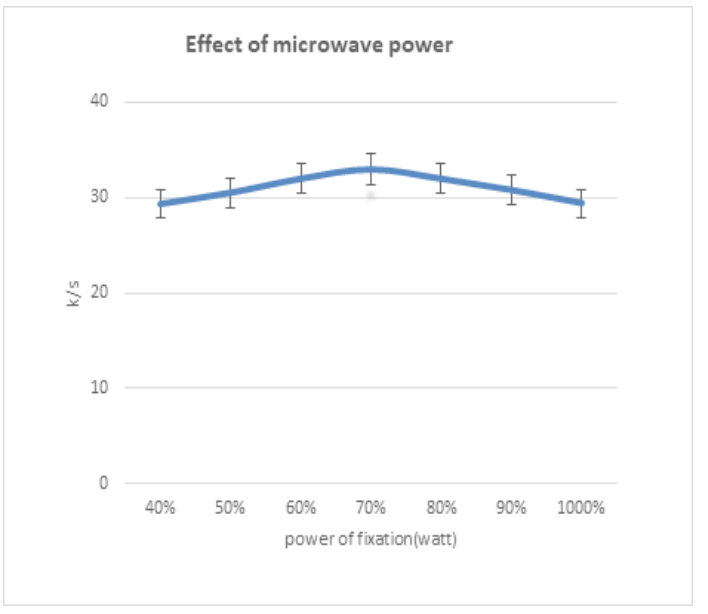

Fig.3. Effect of fixation microwave powers on (K/S) of cotton fabrics at 3 min. 


\section{Effect of microwave fixation time}

Figure 4 comprises the results obtained for the samples printed and fixed via microwave irradiation at various durations $(1,2,3,5,6,7$ and $9 \mathrm{~min}$ ) at optimum microwave power $700 \mathrm{~W}$ obtained from the power's study.

It is clear from the data of Fig. 4 that, as the time of exposure to microwave irradiation increased from 1 to $3 \mathrm{~min}$, the $\mathrm{K} / \mathrm{S}$ of the printed cotton fabrics increased regularly from 29.8 to 33 . But it decreased with a further increase. The current data is expected since increase in the power at constant time is accompanied by increase in the temperature. It reached the maximum value at 3 min, afterwards, the K/S decreased with further increase. It seemed that, under these severe conditions, the produced heat affected the rate of reaction between cellulosic cotton and the reactive dye via either hydrolysis of some dye molecules or thermal decomposition [9].

Since the conversion of microwave radiation to heat energy [7] depends on the presence of polar water molecules, a trial was made to conserve some water molecules and decrease their evaporation and escaping from the printed film, this was done via covering the printed goods with a plastic sheet [35].

Accordingly, the optimum values of fixation time and irradiation power were found to be $3 \mathrm{~min}$ and $700 \mathrm{~W}$.

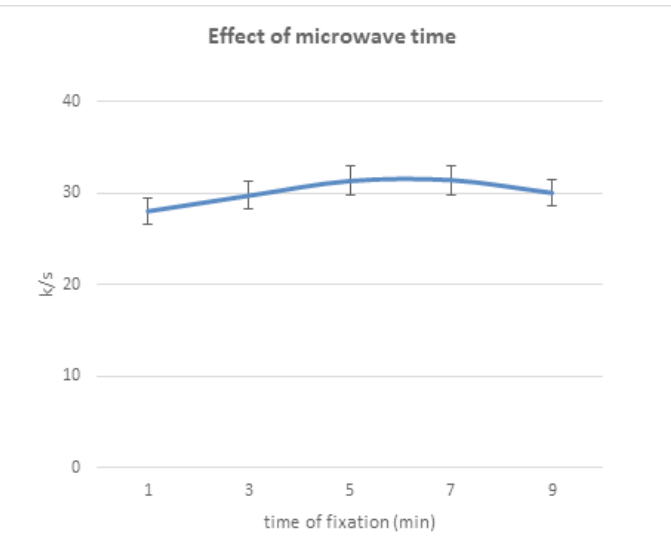

Fig.4. Effect of fixation microwave time on (K/S) of cotton fabrics

A comparison was made to show the efficiency of the proposed technique shown in Fig. 5 and the results revealed that: K/S value $=33$ of treated sample fixed with microwave $(700 \mathrm{~W}$ at $3 \mathrm{~min}$ ) was better than that treated and fixed via conventional thermo-fixation for $5 \mathrm{~min}$ at $180^{\circ}$ 。
$\mathrm{C}$ with $\mathrm{K} / \mathrm{S}=24.3$, or that fixed by steaming for $10 \mathrm{~min}$ at $103^{\circ}{ }^{\circ} \mathrm{C}(31.6)$.

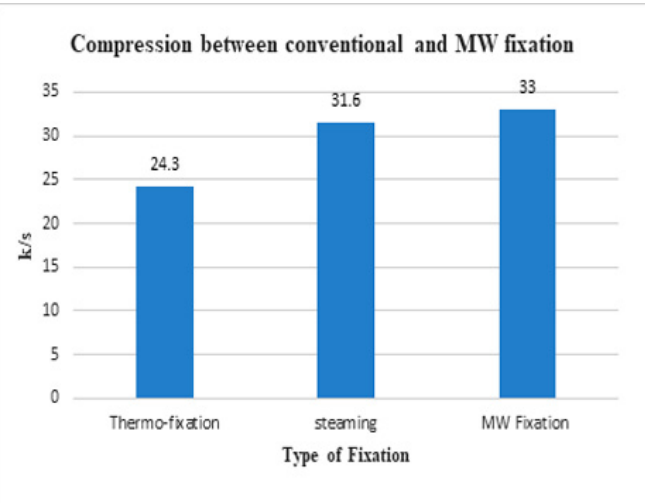

Fig.5. Compression between conventional fixation and microwave fixation.

It is inferred from Fig. 4 that microwave fixation ensured similar color yields in shorter setting time compared to conventional methods. So the new system represents an alternative method with the advantages of time savings and lower energy consumption.

Effect of silver nanoparticles concentration

Figure 6 shows that increasing the concentration of synthesized Ag-NPs resulted in a significant improvement in the color depth of the obtained prints, expressed as K/S values.

The observed data indicates that the increasing is achieved by using higher concentrations of AgNPs. This can be explained by the fact that, high number of spherical Ag-NPs were formed on the surface of the fabric by using more concentrated Ag-NPs colloidal solutions (cf. SEM results, Fig. $9,10)$. According to that, more absorbency of the dyestuff occurred leading to higher $\mathrm{k} / \mathrm{s}$ values.

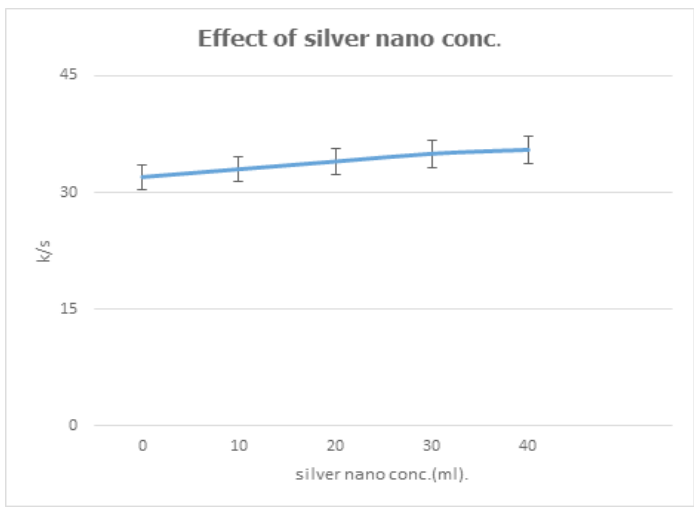

Fig.6 Effect of the concentration of Ag-NPs on K/S value of printed cotton fabrics.

Egypt.J.Chem. 61, No.3 (2018) 


\section{Fastness properties}

Table 1 represents the different color fastness properties (washing, rubbing and light) of all printed cotton fabrics that were measured according to standard methods AATCC Test Methods (61), (8) and (16A), respectively. The results obtained showed that all printed fabrics that were fixed via microwave irradiation exhibited excellent fastness levels to washing and rubbing as well as light. The results are equivalent or even better than the samples that were fixed via conventional methods. These results reflect the efficiency of the proposed technique in producing printed cotton fabric with excellent fastness properties as well as a noticeable reduction in the powers and time that are used for fixation.

TABLE 1. comparison between the printed samples using MW \& Ag-NPs and the conventional printing techniques.

\begin{tabular}{|c|c|c|c|c|c|}
\hline \multicolumn{5}{|c|}{ Fastness properties } & \multirow[t]{3}{*}{$\begin{array}{l}\text { Reactive dye used \& optimum condition } \\
\text { of each fixation type }\end{array}$} \\
\hline \multirow{2}{*}{ Light } & \multicolumn{2}{|c|}{ Rubbing } & \multicolumn{2}{|c|}{ Washing } & \\
\hline & Dry & Wet & Alt. $^{b}$ & St. ${ }^{\mathrm{a}}$ & \\
\hline $4-5$ & 5 & 5 & 5 & 5 & microwave at $700 \mathrm{w}$ for $3 \mathrm{~min}$. \\
\hline $4-5$ & 5 & 5 & 5 & 5 & steaming $\left(103^{\circ} \mathrm{C}\right.$ for $\left.10 \mathrm{~min}\right)$ \\
\hline 4 & 5 & $4-5$ & 5 & 5 & thermo-fixation $\left(180^{\circ} \mathrm{C}\right.$ for $\left.5 \mathrm{~min}\right)$ \\
\hline
\end{tabular}

(a: staining b:alteration) on cotton fabric.

\section{SEM and EDx analysis}

SEM observation of the cotton fibers reveals that the untreated fabric in Fig. 7 has fairly smooth surface, but the surface morphology of the treated fabric in Fig. 8 has been changed dramatically and there are different features on the surface of the fibers, such as grooves and voids and surface roughness. The obtained results were found in compliance with previous studies $[10,19]$. As a result of this treatment, the morphological structure of the cotton fiber is partially destroyed, which promotes the adsorption and permeation of the dye molecules into the cotton fibers, resulting in improving the extent of reaction between the reactive dye and the cotton fibers.

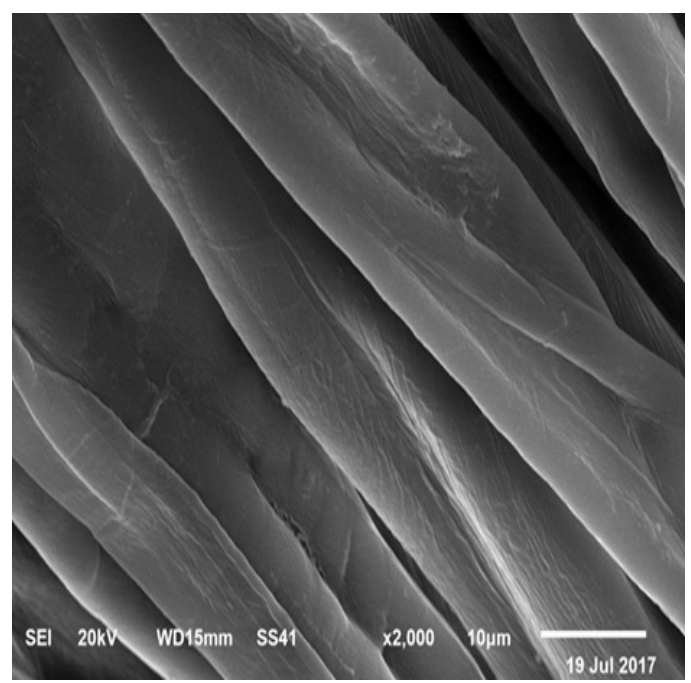

Fig.7 SEM image of cotton fabric without treatment.

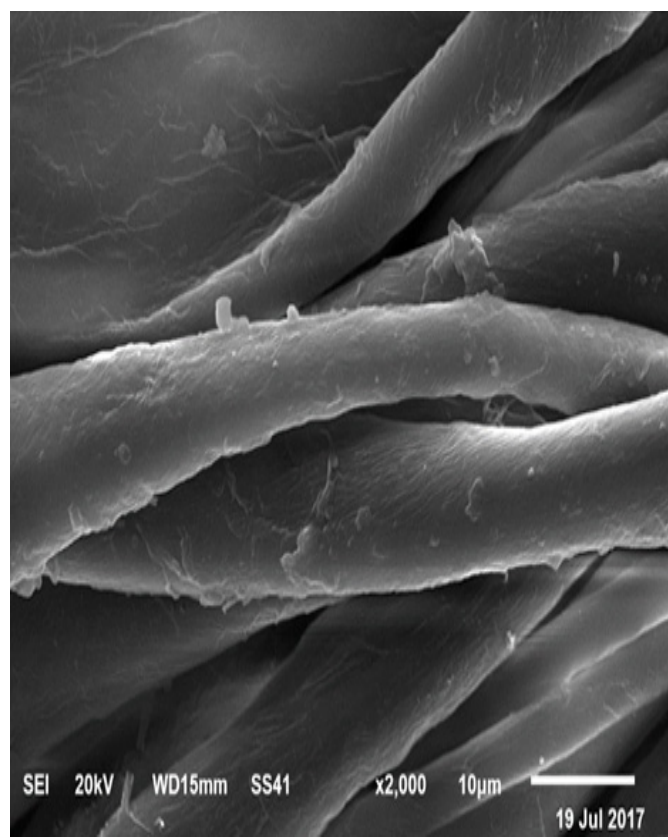

Fig.8 SEM image of treated cotton fabric with microwave (Condition 600 Wfor $5 \mathrm{~min}$ before printing) NPS

SEM and EDx for samples printed with $\mathrm{Ag}$ -

SEM images in Fig. 9, 10 showed the nano silver particles on the fiber surface that incorporated into cellulosic fibers in cotton fabric. Ag-NPs were successfully distributed on the surface of all examined printed fabrics. Nano silver particles were observed in EDEX results in Fig. 11 with, $0.56 \%$ weight and $0.08 \%$ atomic

Egypt.J.Chem. 61, No.3 (2018) 


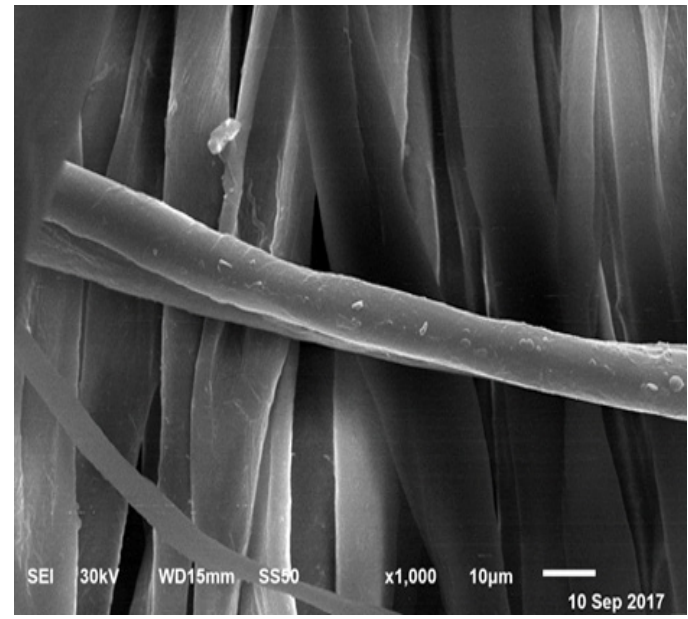

Fig. 9 SEM image of treated cotton fabric with AgNPs.

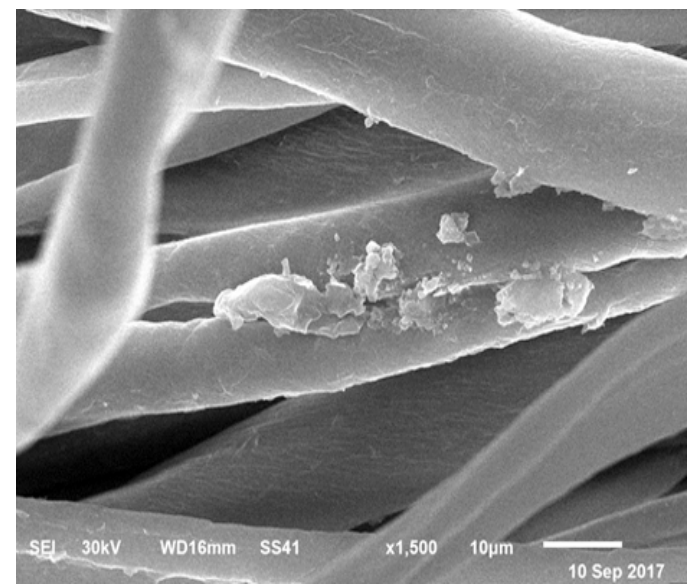

Fig. 10. SEM image of treated cotton fabric with AgNPs.

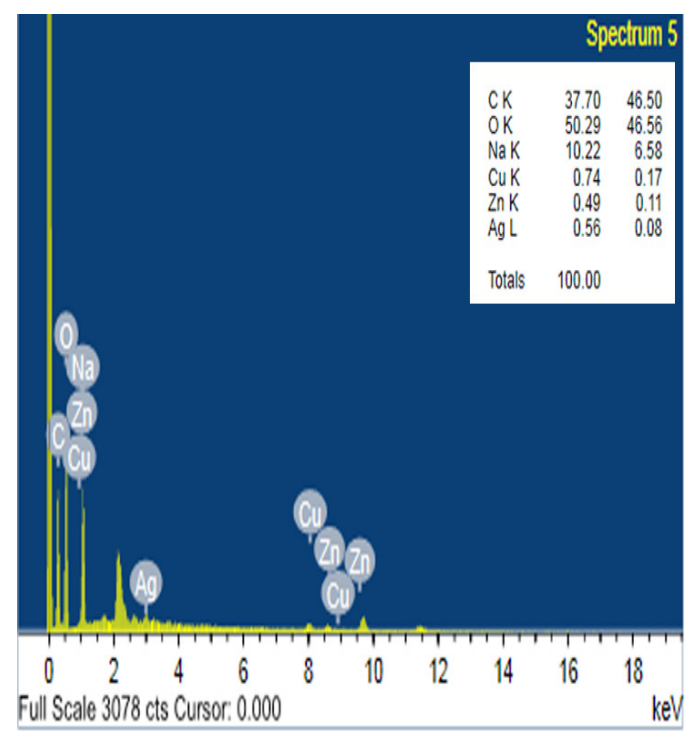

Fig. 11. EDX of treated cotton fabric with Ag-NPs. absorption of the analyzed spot in the fiber surface.

\section{Mechanical testing}

The changes in the mechanical properties (tensile strength and percentage Elongation) of untreated cotton fabrics and those exposed to microwave treatments are assessed and the attained results are symbolized in Table 2 .

The analysis proved that the microwave power and time of the treatment have significant effect on fabric breaking load. Elongation decreasing trend was detected assuring that as both variables levels

TABLE 2. Effects of microwave treatment on mechanical properties.

\begin{tabular}{ccc}
\hline $\begin{array}{c}\text { Treated sample } \\
\text { with microwave }\end{array}$ & $\begin{array}{c}\text { Untreated } \\
\text { sample }\end{array}$ & Samples \\
\hline 357.6 & 412.0 & $\begin{array}{c}\text { Force(N) } \\
7.88\end{array}$ \\
Rate $: 100 \mathrm{~mm} / \mathrm{min}$. & $\begin{array}{c}\text { Elongation } \\
(\%)\end{array}$ \\
\hline
\end{tabular}

increased the fabric breaking load and elongation decreased [10].

\section{Antimicrobial activity}

Antimicrobial properties for fabrics printed with Ag-NPs are shown in Table 3. The results showed that the untreated printed samples $\left(\mathrm{T}_{0}\right)$ were not affected and there were no inhibition areas, while the treated printed cotton samples using Ag-NPs have an excellent antimicrobial activity against $S$. aureus, E. coli and C. utilis in $\mathrm{T}_{8}$, but they have negative effect in other concentrations $\left(\mathrm{T}_{1}-\mathrm{T}_{7}\right)$.

Bacillus subtilisisa Gram positive and endospore forming bacterium which have a negative effect by Ag-NPs. The lowest value $\left(82 \mathrm{~mm}^{2}\right)$ of antibacterial activity was in the case of the Staphylococcus aureus which is Gram positive bacterium and non-spore former. Antibacterial activity increased $\left(155 \mathrm{~mm}^{2}\right)$ in the case of the Gram negative and non-spore forming bacterium (E.coli). On the other hand, the yeast $C$. utilis achieved the highest value of antimicrobial activity being $220 \mathrm{~mm}^{2}$.

The finding of Keuk-Jun et al. [36] could explain these results, where he reported that, Ag-NPs have proven antibacterial activity and became promising in relation to fungi. Antifungal activities have become more common in recent 
years. Moreover, the properties of Ag-NPs vary according to their size and shape [37]. The reason for improvement in the antimicrobial functionality is referred to the interaction of the negatively charged cell walls of the pathogens with the positively charged cationic sites of the antimicrobial agent, which in turn change its physical and chemical properties causing the interruption of the cell membrane functions and protein activity, as well as the inability to multiply. Silver nanoparticles release the silver ions producing higher biocidal effect on the microorganisms [3].

The sizes of Ag-NPs play an important role in their antimicrobial activity. A higher antimicrobial activity was observed only when Ag-NPs between 20 to $25 \mathrm{~nm}$ but not in 80 to 90 nm range [38]. Ag-NPs with a diameter $13.5 \pm$ $2.6 \mathrm{~nm}$ are effective against yeast [39]. Ag-NPs have a bioactivity role because of their large surface area and high reactivity. Ag-NPs metal particles exhibit remarkable physical, chemical, and biological properties [37]. The reason for fungal death could be explained by the finding of Long et al. [40] where Ag-NPs may accumulate in the cytoplasmic membrane, causing increase in permeability of the fungal cell and leading to the death.

It is known that nano-materials exhibit strong inhibiting effects towards a broadened spectrum of bacterial strains, especially Ag-NPs which displayed good activity against all the indicator pathogens, showing a potential broad spectrum antimicrobial activity [41]. Consequently, adding

TABLE 3. Effect of Ag-NPs on antimicrobial properties of printed cotton samples.

\begin{tabular}{ccccc}
\hline & \multicolumn{4}{c}{ Inhibition zone area $\left(\mathbf{m m}^{2}\right)^{*}$} \\
\cline { 2 - 5 } Sample & Bacillus cereus & Staphylococcus aureus & Escherichia coli & Candid utilis \\
\hline Printed (T8) & 0 & 82 & 155 & 220 \\
Printed (T0) & 0 & 0 & 0 & 0 \\
\hline
\end{tabular}

* Area of antimicrobial clear zone $\left(\mathrm{mm}^{2}\right)$ after incubation period $(24 \mathrm{~h})$

Ag-NPs to the printing paste brings a significant improvement in the antimicrobial activity of prints against pathogens.

\section{Conclusion}

It can be concluded that the present work aims to green processing of cotton fabrics using recent innovative technologies, viz., microwave irradiation and nanotechnology for functionalization of fabrics which refers to improvement in printability, interaction with silver nanoparticles to impart antimicrobial activity to the fabric. These recent technologies are economically feasible, secure and acquire superiority over other conventional methods. The influence of microwave treatment on cotton fabrics was investigated. It is observed that the microwave irradiation eliminated the use of heat energy and time of fixation. Also, the color strength expressed as K/S of microwave treated cotton was higher than untreated ones. The result of SEM and EDX measurements confirmed the uniform distribution of Ag-NPs on treated cotton fabrics. The nano-printed fabrics have excellent color fastness properties and highly durable antimicrobial activity.

\section{$\underline{\text { References }}$}

1. Bashar M.M. and Khan M.A., An Overview on Surface Modification of Cotton Fiber for Apparel Use. Polym. Environ., 21, 181-190 (2013).

2. Ibrahim N.A., Eid B.M. and El-Batal H., A novel approach for adding smart functionalities to cellulosic fabrics.Carbohydr. Polym, 87, 744-751 (2012).

3. Ibrahim N.A., Eid B.M., Abd El-Aziz E., Abou Elmaaty T.M. and Ramadan S. M., Multifunctional cellulose-containing fabrics using modified finishing formulation. RSC $A d v$., 7, 3219-3230 (2017).

4. Büyükak B.Y.,Usage of microwave energy in Turkish textile production sector. Energy Procedia, 14, 424-431 (2012).

5. Liu L., Li Y., Fang Y. and Chen L., Microwaveassisted graft copolymerization of caprolactone onto chitosan via the phthaloyl protection method. Carbohydrate Polymers, 60 (3), 351-356 (2005).

6. Zielinski M., Ciesielski S., Cydzik-Kwiatkowska A., Turek J., Debowski M., Influence of microwave

Egypt.J.Chem. 61, No.3 (2018) 
radiation on bacterial community structure in biofilm. Process Biochemistry,42 (8), 1250-1253 (2007).

7. Haggag K., El Molla M. and Mahmoud Z.M., Dyeing of cotton fabrics using reactive dyes by Microwave irradiation technique. Indian Journal Of Fibers \& Textile Research, 39 (4), 406-410 (2014).

8. Hebeish A., Abou Elmaaty T., Ramadan M. and Magdy H., Microwave and plasma treatments for functionalization of polyester fabrics. International Journal of Current Microbiology and Applied Sciences (IJCMAS), 4 (7), 703-715 (2015).

9. Abdel-Thalouth I., Ragheb A.A., and et.al, Application of microwave in textile printing of cellulosic fabrics. Research Journal of Chemical Sciences, 4 (9), 41-46 (2014).

10. Ramadan M.A., Almetwally A.A. and Mohamed S.S., The effect of microwave treatment and weave structure on cotton fabric. Textile Asia, 46, 34-41 (2015).

11. Su Y., Cotton pad dyeing microwave fixation technology research. Journal of Dyes and Dyeing, 49 (2), 23-26 (2012).

12. Yuanjun L., Xueyan W., Bingzheng S., Modified cotton fabric dyeing effect evaluation. Journal of $X i$ 'an Engineering University, 26 (5), 576-580 (2012).

13. Xue Z., Jin-xin H., Improvement of dye ability of wool fabric by microwave treatment, Indian Journal Of Fibers \& Textile Research, 36, 58-62 (2011).

14. Sun H., et al., The improvement of dye ability of flax fiber by microwave treatment. Pigment \& Resin Technology, 34 (4), 190-196 (2005).

15. Öner E., Y. Büyükakinci and N. Sökmen, Microwave assisted dyeing of poly (butylene terephthalate) fabrics with disperse dyes. Coloration Technology, 129 (2), 125-130 (2013).

16. Ahmed K.A., et al., Microwave Synthesis - A Prospective Tool for Green Chemistry and Its Textile Application, Saarbrücken, Germany: LAP LAMBERT Academic Publishing AG \& Co. KG (2013).

17. Jingya L., Jianxi R., Zhifeng C., Mei N., Wensheng H., and Jinming D., Effect of Microwave treatment on the properties of PET Fiber. Advanced Materials Research, 557 (559), 1420-1422 (2012).
18. Cabrales L., Study on Influences of Microwave Irradiation on Polyester fiber Performance. Applied Surface Science, 258, 4636-4641 (2012).

19. Haggag K., A Review Article of Microwave Irradiation and its Application in Textile Industries, Science Publishing Group (2014).

20. Lok C., Ho C., Chen R., He Q., Yu W., Sun H., Tam P. K., Chiu J. and Che C., Silver nanoparticles: partial oxidation and antibacterial activities. $J$ BiolInorg Chem., 12, 527-534 (2007).

21. Gutierrez A., Olive P. L., Banuelos A., Orrantia E., and et al, Characterization and evaluation of antimicrobial and cytotoxic effect of silver and titanium nanoparticles. Nanomedicine: Nanotechnology, Biology, and Medicine, 6, 681688 (2010).

22. Ibrahim N. A., Eid B. M., Abd El-Aziz E. and Abou Elmaaty T. M., Functionalization of linen/cotton pigment prints using inorganic Nano structure materials. Carbohydr. Polym. 97, 537-545 (2013).

23. Ibrahim N. A., Eid B. M., Abou Elmaaty T. M. and Abd El-Aziz E.,A smart approach to add antibacterial functionality to cellulosic pigment prints. Carbohydr. Polym, 94, 612-618 (2013).

24. Ibrahim N. A., Abou Elmaaty T. M., Eid B. M. and Abd El-Aziz E., Combined antimicrobial finishing and pigment printing of cotton/polyester blends. Carbohydr. Polym. 95, 379-388 (2013).

25. Ibrahim N. A., Abd El-Aziz E., Eid B. M. and Abou Elmaaty T.M., Single-stage process for bifunctionalization and eco- friendly pigment coloration of cellulosic fabrics. J. Text. Inst., 107, 1022-1029 (2015).

26. Lin X., Zou F., Chen X. and Tang B., Functional modification of Nylon fabrics based on noble metal nanoparticles. IOP Conf. Ser.: Mater. Sci. Eng., 231, (2017).

27. Islam Sh., Butola B. S., and Mohammad F., Silver nanomaterials as future colorants and potential antimicrobial agents for natural and synthetic textile materials. $R S C A d v$.,6, $44232-44247$ (2016).

28. Gokarneshan N. and Velumani K., Application of Nano Silver Particles on Textile Materials for Improvement of Antibacterial Finishes. Glob. J. Pharmaceu. Sci., 2, 1-4 (2017).

29. Azzaz N., El-Kadi S., , Said K.A., Mahmoud M., Antimicrobial Activities for Green Synthesis of Silver Nanoparticles Using Stevia rebaudiana and 
Plucheadioscoridis Leaves. International Journal of Agricultural and Biosystems Engineering, 2 (6), 54-66 (2017).

30. ASTM, Standard test method for tensile properties of single textile fibers. D 3822-96 (2000).

31. Textiles, Test for color fastness, part C01: Color Fastness to Washing. Test 1, ISO 105C01 (1998).

32. Tera light fastness tester, Egyptian Patent No. 15182 (1981).

33. Textiles, Tests for colour fastness, Colour fastness to artificial 34. Weathering, Xenon arc fading lamp test, BS EN ISO 105-B04 (1997).

34. AATCC Test Method, Antimicrobial activity determination (1993).

35. Haggag K., Ragheb A.A., Abdel-Thalouth I., Rekaby M., El-Hennawi H.M. and Shahin A.A., Pigment Printing of Cotton Fabrics using Microwave Irradiation. Research Journal of Chemical Sciences, 5 (4), 20-25 (2015).

36. Keuk-Jun K., Sung W. S., Moon S., Choi J., Kim J. G. and Lee D. G. Antifungal effect of silver nanoparticles on Dermatophytes. J. Microbiol. Biotechnol, 18 (8), 1482-1484 (2008).
37. Lok C., Ho C., Chen R., He Q., Yu W., Sun H., Tam P. K., Chiu J. and Che C., Silver nanoparticles: partial oxidation and antibacterial activities. J Biol Inorg Chem. 12, 527-534 (2007).

38. Martinez F., Olive P. L., Banuelos A., Orrantia E., Nino N., Sanchez E. M., Ruiz F., Bach H. and Av-Gay Y., Synthesis, characterization, and evaluation of antimicrobial and cytotoxic effect of silver and titanium nanoparticles. Nanomedicine: Nanotechnology, Biology, and Medicine, 6, 681-688 (2010).

39. Varner K.; Manager T. O., Sanford J., Leader T. O., El-Badawy A., Feldhake D. and Venkatapathy R., State of The Science Literature Review: Everything Nano silver and More. Environmental Protection Agency Office of Research and Development Washington. DC, U.S. 20460. (2010).

40. Long N. V., Joly C. and Dantigny P., Active packaging with antifungal activities. International Journal of Food Microbiology. 220, 73-90 (2016).

41. Gokarneshan N. and Velumani K., Application of Nano Silver Particles on Textile Materials for Improvement of Antibacterial Finishes.

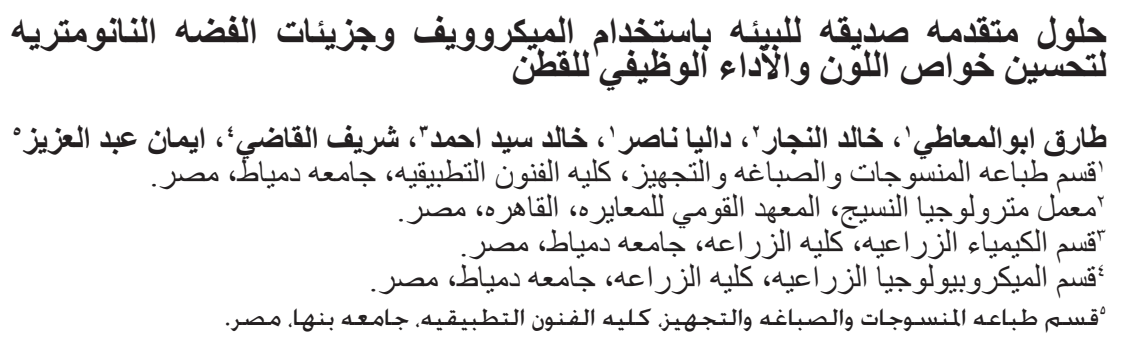

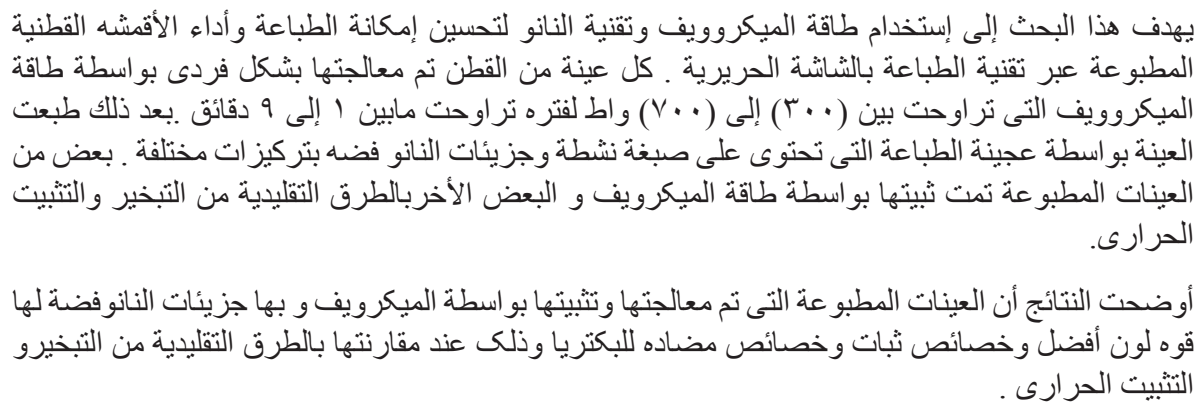

Egypt.J.Chem. 61, No.3 (2018) 